\title{
EXPERIÊNCIAS DE FORMAÇÃO E NARRATIVAS EDUCACIONAIS DE PROFESSORES BRASILEIROS EM VIAGEM AOS ESTADOS UNIDOS (1929-1935)
}

\section{SILMARA FATIMA CARDOSO}

Secretaria Municipal de Educação de São Paulo - CEU EMEF Butantã Universidade Aberta/UAB (Butantã)

RESUMO

Este estudo tem por pretensão analisar a história e os fatores que levaram Anísio Teixeira, enquanto Diretor Geral da Instrução Pública, no antigo Distrito Federal, e a Associação Brasileira de Educação - ABE a investir em viagens de professores brasileiros aos Estados Unidos. $O$ objetivo de Anísio Teixeira e da ABE concorriam para que esses professores imbuídos de uma formação pedagógica eficiente, adquirida no país considerado à época como referência, pudessem ser os principais atores na renovação e regeneração do ensino e da sociedade brasileira. Palavras-chave: Viagem pedagógica. Professores brasileiros. Experiências de formação. Narrativas educacionais.

\section{ABSTRACT EXPERIENCES OF FORMATION AND EDUCATIONAL}

\section{NARRATIVES OF BRASILIAN TEACHERS TRAVELING TO THE UNITED ESTATES (1929 - 1935)}

This Study has the pretention to analyze the history and facts that lead Anísio Teixeira, when General Director of Public Instruction in the old Federal District and the Brasilian Educational Association $A B E$ to invest in travel of Brazilian teachers to the United States. The objective of Anísio Teixeira and ABE was for these teachers imbued in a effective teacher training acquired in the country concerned in the time as a reference could be the main actors in the renewal and regeneration of teaching in the Brazilian Society.

Keywords: Educational Travel. Brazilian teachers. Formation experience. Educational narrative.

\section{RESUMEN EXPERIENCIAS DE FORMACIÓN Y NARRATIVAS}

\section{EDUCATIVAS DE PROFESORES BRASILEÑOS EN VIAJE A} LOS ESTADOS UNIDOS (1929-1935).

Este artículo tiene el propósito de analizar la historia y los factores que llevaron Anísio Teixeira como Director General de Instrucción 
Pública en el antiguo Distrito Federal y la Associação Brasileira de Educação - ABE para investir en viajes de maestros brasileños a los Estados Unidos. El objetivo de Anísio Teixeira y de la ABE compitió por estos maestros imbuidos de una formación pedagógica eficiente adquirida en el país considerado en ese momento como una referencia, podrían ser los principales actores de la renovación y la regeneración de la enseñanza y de la sociedad brasileña.

Palabras claves: Viajes educativos. Profesores brasileños. Experiencias de formación. Narrativas educativas.

\section{Considerações iniciais}

Este artigo tem por pretensão analisar a história e os fatores que levaram Anísio Teixeira, enquanto Diretor Geral da Instrução Pública, no antigo Distrito Federal, e a Associação Brasileira de Educação - $A B E$ a investir em viagens de professores brasileiros aos Estados Unidos. Para tanto, utilizo como fontes de estudo cartas (pessoais, de ofício, de apresentação), fichas cadastrais, decretos, revistas educacionais e jornais, onde estão publicados, seja de forma parcial ou total, os relatórios de viagem e as entrevistas concedidas pelos professores, tratando dos processos da viagem, e dos estudos nas instituições norte-americanas. Por fim, apresento livros publicados por algumas viajantes, relacionados assunto, que estudaram nas instituições educacionais norte-americanas, tornando-as especialistas em novos campos de saberes.

Este artigo será desenvolvido em quatro tópicos. Primeiramente, trato dos professores eleitos para a viagem de estudos. Quem era escolhido para viajar e por quê? Quais eram os critérios seletivos? Logo, então, a reflexão é sobre o destino privilegiado da viagem, os Estados Unidos da América. Qual a relação do Brasil com os Estados Unidos? Por que esse país se torna o destino privilegiado, nas viagens de estudo? Como foi o percurso da viagem? Que instituições educativas foram visitadas pelos professores brasileiros? Depois, proponhome a fazer uma reflexão sobre a viagem como parte da formação. Para tanto, serão investigados as instituições e os temas de estudo que os professores viajantes desenvolveram resultando daí uma produção especializada. Por fim, examino as experiências transformadas em relatos e os meios privilegiados de sua publicação, que foram as revistas pedagógicas e os jornais.

O referencial teórico-metodológico desse artigo se apoia nas viagens pedagógicas, e acompanha uma das linhas dos estudos historiográficos que tem o seu interesse voltado para as pesquisas sobre viagens e os escritos produzidos pelos viajantes, contemplando discursos e representações sobre aspectos culturais, políticos, sociais e educacionais de países e sociedades.

Compreender os sentidos e propósitos das viagens, como o deslocamento de professores brasileiros para os Estados Unidos com a finalidade de estudar o seu sistema educacional, nos ajudam no entendimento das influências, apropriações e possiveis leituras de um modelo de ensino estrangeiro, no campo educacional brasileiro e na formação e atuação dos professores viajantes.

Anísio Teixeira valorizou a política da formação em viagem, quando da sua adminis- 
tração do ensino público, na antiga capital da república. Ele, que já havia tido experiências de formação em viagens, quando, em 1925, conheceu e observou instituições educativas europeias, em 1927, instituições educativas norte americanas e, no ano de 1928, fez um curso de especialização no Teachers College da Universidade de Columbia, realizando ainda muitas outras viagens ao país norte-americano, compreendia bem o que uma viagem de estudos poderia proporcionar à formação intelectual e especializada de professores.

Assim como Anísio Teixeira, a ABE esteve envolvida com os rumos da educação brasileira. Foi a grande promotora de incentivo às viagens de estudo e de difusão de um pensamento pedagógico estrangeiro. Teve forte influência na elaboração de leis que traçaram diretrizes e bases da educação e planos nacionais de educação. Como bem afirma Carvalho (1998, p. 31):

\begin{abstract}
A ABE foi a grande promotora e um dos instrumentos mais eficazes de difusão do pensamento pedagógico europeu e norte-americano, e um dos mais importantes, se não o maior centro de coordenação e de debates para o estudo e solução de problemas educacionais, ventilados por todas as formas, em inquéritos, em comunicados à imprensa, em cursos de férias e nos congressos que promoveu nas capitais dos Estados.
\end{abstract}

O objetivo de Anísio Teixeira e da ABE, em enviar professores para estudar nos Estados Unidos, concorria para que os mesmos, imbuídos de uma formação pedagógica considerada eficiente, pudessem ser os principais atores da renovação e regeneração do ensino e da sociedade brasileira, pois como diz Moraes (2011, p. 248):

[...] 0 discurso da renovação do Brasil pela educação, nas variantes do início da República e na década de 1920, concorreu para constituir representações e atribuir sentidos à profissão docente: como regeneradora dos costumes, salvadora da pátria, construtora da nação, responsável pela iluminação e modernização da sociedade.

É importante refletir que a circulação de ideias educacionais se tornou uma prática e um modus operandi e a viagem de estudos para o exterior, com o objetivo de aprofundamento teórico, comunicava simbolicamente uma ação considerada adequada: ser moderno, estar atualizado, ter estado, ter visto, ter vivido uma situação de experiência, engendrando uma prática, um ritual, tornando a busca de modelos uma cultura de formação de professores e de atuação de reformadores.

Se não havia no Brasil, nos séculos XIX e $X X$, instituições suficientes e específicas para a formação, em contrapartida, também não havia especialistas capacitados para atuar em determinados campos de conhecimento. Dessa forma, a viagem pedagógica era considerada uma formação, por que, além de observarem as escolas, os professores realizavam cursos nas universidades, tornando-se especialistas.

Essa é uma das razões que levaram professores brasileiros a partir em viagem de estudos. Além de que, a áurea que se tinha de estudar em um país considerado de primeiro mundo, desenvolvido, com um ensino superior sistematizado e de qualidade, era muito forte. $E$ ademais, quando os sujeitos voltavam de suas viagens, certamente era mais facilitada a sua ocupação em cargos de prestígio.

Houve casos de professores primários que foram se especializar em instituições de países estrangeiros, estudando por meses ou anos, e, quando voltaram, foram lecionar, na Escola de Professores, disciplinas específicas, como as metodologias: de português, de matemática, de ciências etc. Ou, ainda, tornavam-se professores do ensino secundário ou ocupavam cargos de coordenação, chefia ou direção, nas escolas de ensino primário, secundário ou na escola normal. Assim, atingindo um grau mais 
elevado de ocupação em um cargo público educacional, alguns professores primários foram ministrar aulas na UDF - Universidade do Distrito Federal, na escola de professores.

Isto significava se tornar formadores/as de professores/as; significava também colocar em prática o novo repertório pedagógico conhecido nas instituições educativas estrangeiras, atuando em consonância com os objetivos dos reformadores e homens de Estado que enviavam esses professores para uma missão pedagógica. Assim, o discurso da renovação da educação brasileira estabeleceu uma formação especializada ao professorado brasileiro.

Compreende-se então que a viagem, além de propiciar uma formação especializada, possibilitava também uma ascensão e status profissional, pois, passar da categoria de professor primário para professor do ensino superior, é um salto grande. Hoje seria impossível pensar em algo parecido, já que a ideia de formação é outra.

Mignot e Silva (2011) observam que uma viagem para um país estrangeiro, em finais do século XIX, significava um peso e, ao mesmo tempo, uma experiência desafiadora para um professor primário brasileiro, capaz de funcionar como um divisor de águas, um marco na trajetória profissional e pessoal desse professor, para além da ideia de distinção entre os demais no campo educacional.

Isto faz com que as viagens carreguem uma aura, diferenciando uns em relação aos outros. Aqueles que viajavam tinham um elemento de distinção; conquistavam novos conhecimentos e absorviam outros códigos culturais. De uma viagem, o viajante sempre voltava mais experiente, ampliando e enriquecendo o seu universo cultural, suas relações sociais, de prestígio, e conquistas profissionais.

A viagem constituía etapa importante da formação. As relações de dependência que figuravam a superioridade europeia e norte-a- mericana, ao lado de uma situação social brasileira em que, ao mesmo tempo, valorizando uma formação especializada, apresentava opções precárias de educação, criou um campo fértil para a formação em viagem.

Diretores, administradores do ensino público, chefes de Estado, organizações e associações nacionais e internacionais investiram em viagens pedagógicas. A ABE financiou viagens para professores do Rio de Janeiro e São Paulo. O objetivo era que esses professores adquirissem conhecimentos, no que diz respeito a um sistema de ensino considerado modelar, para, então, cooperarem na organização do campo educacional brasileiro

No Brasil, a iniciativa das viagens de estudo aconteceu, ainda no período monárquico, quando professores, diretores de estabelecimentos educacionais e inspetores de instrução pública percorreram países estrangeiros, participando inclusive como representantes do Império do Brasil nas celebradas Exposições Internacionais (SCHULER, 2007).

Carvalho (2001) observa que essas viagens continuam, com o fim do Império e o início da República, pois havia um empenho, por parte daqueles que pensaram a modernização do país, na fundação de escolas e na organização de sociedades destinadas a propagar a instrução popular. Essa geração concentra seu interesse de modernização em iniciativas e inovações pedagógicas, que vinham de países estrangeiros, imprimindo um novo perfil à instrução pública brasileira.

Assim, na tentativa de solucionar os problemas da educação, diretores de ensino e associações educativas enviaram professores em busca das modernas práticas educacionais adotadas nos países considerados civilizados. Almejavam encontrar informações e significações que os auxiliassem a traçar projetos para um ensino cada vez mais afinado com as luzes da civilização, condição de constituição 
de uma grande nação. As reflexões em torno das experiências vividas pelas nações consideradas desenvolvidas acabavam por produzir sentidos para as ações educativas futuras (CHAMON, 2005).

\section{Os professores eleitos para a viagem de estudos}

Em 1929, quando o professor Carlos Delgado de Carvalho volta de uma de suas viagens aos Estados Unidos, apresenta à ABE um convite da Fundação Carnegie Endowment para receber professores brasileiros em missão de estudos. O professor Delgado de Carvalho diz que, nos Estados Unidos, mobilizou algumas pessoas e organizações para conseguir o financiamento da viagem dos professores brasileiros, para que pudessem obter uma formação e visitar as instituições educacionais.

Assim, com o apoio norte-americano pela fundação Carnegie Endowment, a ABE organiza um grupo de 10 professores selecionados pelo Conselho Diretor, para seguir em viagem, no período de férias, nas suas respectivas especialidades. A estadia seria custeada pela Carnegie Endowment e o programa seria elaborado pelo Institute of International Education. Abriram-se sete vagas para professores do Rio de Janeiro e três para São Paulo.

Dentre os selecionados de São Paulo, estiveram Carolina Coelho do Rego Rangel, Noemy da Silveira Rudolfer e Eunice Caldas. Já, entre os selecionados do Rio de Janeiro, estiveram Consuelo Pinheiro, Otávio B. Couto e Silva, Décio Lyra da Silva, Henry Othon Leonardos, Julieta Arruda, Laura Jacobina Lacombe, Maria dos Reis Campos. O professor Carlos Delgado de Carvalho foi o coordenador do grupo.

Assim como a ABE, muitos administradores da educação pública, no intuito de promover a reforma educacional, investiram na

1 Informações retiradas da Revista Schola, Rio de Janeiro, 1930, no 1-9. formação de educadores, aderindo à política das viagens pedagógicas. Anísio Teixeira foi um desses administradores do ensino, que, além de ter participação ativa nessa entidade, também investiu em viagens para professores brasileiros, aos Estados Unidos, pois ele já tinha tido experiências de viagens de estudo.

No ano de 1932, professoras que atuava no Instituto de Educação e nas escolas municipais do antigo Distrito Federal foram selecionadas para uma missão de estudos nos Estados Unidos, no intuito de se especializarem em determinada área do conhecimento ou da disciplina que ministravam no exercício da docência. Entre os nomes escolhidos estavam Cecília Meirelles, Ceição de Barros Barreto, Clarisse de Souza, Consuelo Pinheiro, Clotilde Matta e Silva, Eduardo Bastos Agostini, Juracy Silveira, Maria dos Reis Campos, Margarette Andrade, Ruth Gouvea, Sebastiana Henriquete de CarvaIho e Stella Muniz Aboim.

Gustavo Lessa, professor de educação comparada, na Escola de Professores do Instituto de Educação, foi incumbido por Anísio Teixeira para coordenar esse grupo, pois ele já tinha viajado várias vezes e conhecia bem os Estados Unidos, a língua, a cultura e as instituições de ensino.

Assim, a grande maioria dos professores selecionados para seguir em viagem já tinha relações estabelecidas no grupo que estava envolvido com a $A B E$ ou no grupo que atuava nos quadros do magistério carioca, quando Anísio Teixeira era Diretor Geral da Instrução Pública, no período de 1931 a 1935. Na ABE, os professores viajantes eram membros ativos, organizavam as conferências, publicavam na revista organizada pela $A B E$, inicialmente chamada Schola e depois Educação. Tiveram, também, uma intensa participação na direção do ensino, atuando nas chefias e nos cargos de coordenação e direção. 
Em dezembro de 1934, Antonio Carneiro Leão, Carlos Delgado de Carvalho e Manoel Bergström Lourenço Filho são designados por Anísio Teixeira para uma viagem de estudos aos Estados Unidos da América, com o objetivo de verificar vários aspectos da moderna educação americana e de representar a Prefeitura do Distrito Federal, em duas reuniões de educadores americanos da Progressive Education Association, em Atlantic City, Nova Iorque. Todos eles atuaram na presidência e vice-presidência da ABE; e estiveram envolvidos de maneira intensa nas atividades da associação e também nas atividades educativas, na direção da instrução pública no Rio de Janeiro.

Em 1933, com o apoio da direção da instrução pública do Rio de Janeiro, quando Anísio Teixeira era o seu diretor, Francisco Venancio Filho parte para os Estados Unidos, para realizar estudos de especialização na Universidade de Columbia. Francisco Venancio Filho foi presidente da $A B E$ e teve participação ativa nos quadros do magistério carioca.

Consuelo Pinheiro e Maria dos Reis Campos integraram a comissão da viagem financiada pela $A B E$, em 1929, e também a financiada pela Direção da Instrução Pública do Rio de Janeiro, em 1932. As duas professoras eram sócias da ABE. Consuelo Pinheiro trabalhou como secretária da Comissão Executiva da Quarta Conferência Nacional de Educação, em 1931, promovida pela ABE. Já Maria dos Reis Campos foi eleita, em reunião promovida pelo Conselho Diretor da associação, em 27 dezembro de 1924, para coordenar a sessão de Ensino Primário. Ambas aturam em atividades educativas na direção da instrução pública no Rio de Janeiro.

Celina Padilha, que havia viajado em 1933 aos Estados Unidos para estudos do ensino primário, atuou na $A B E$ como presidente da Seção de Ensino Primário e também pertenceu aos quadros do magistério carioca. No perío- do de 8 a 14 de outubro de 1928, aconteceu a Primeira Semana de Educação que teve, como membro de sua comissão organizadora, Celina Padilha. Ela também participou da I Conferência Nacional de Educação, que aconteceu em 1927, em Curitiba, e foi organizada pela ABE. Nessa conferência, Celina Padilha apresentou a tese: Sobre a educação sexual, posicionando-se a favor da coeducação.

Aracy Muniz Freire e Maria Junqueira Schmidt viajaram juntas, em 1934, aos Estados Unidos, para estudos de orientação educacional, com financiamento e apoio do diretor Anísio Teixeira. Não foi possível saber se elas foram sócias da $A B E$, o que se sabe é que tiveram publicações na Revista Educação, da ABE, e também ministraram palestras nessa entidade. Essas professoras pertenceram aos quadros do magistério carioca, com uma imensa produção e participação em projetos referentes à orientação educacional.

Do grupo de professores do antigo Distrito Federal selecionados por Anísio Teixeira para viajar aos Estados Unidos, alguns faziam parte dos quadros da Associação Brasileira de Educação, a exemplo de Gustavo Lessa, que foi membro ativo e um dos fundadores da $A B E$, ocupando o cargo de secretário da associação, quando Delgado de Carvalho foi vice-presidente e Afranio Peixoto presidente.

Sobre a participação de Cecília Meireles nos quadros da ABE, Pimenta (2008, p. 70) diz que, embora ela fosse "uma divulgadora das concepções e dos trabalhos dos educadores renovadores e não apenas uma simples entusiasta, Cecília jamais participou como membro da ABE". No ano de 1935, a professora Ceição de Barros Barreto havia sido convidada pela "National Federation of Music Clubs (BARBOSA, C., 1935)" para fazer parte do Congresso Internacional que reuniu, em Los Angeles, vários estudiosos de música e educação musical. Aproveitando essa ocasião, a professora 
foi incumbida por Anísio Teixeira de estudar a orientação geral do ensino artístico musical da nação norte-americana. A professora Ceição de Barros Barreto visitou várias universidades e escolas que eram referências no ensino de música. Ceição de Barros Barreto, "que teve importante participação em comissões e projetos vinculados ao processo de institucionalização da música e da educação musical no Brasil, a partir dos anos 30" (YGAYARA-SOUZA, 2011, p. 220), foi membro do Conselho Diretor da ABE.

Professora, tesoureira e ativa participante nas atividades "silenciosas" da ABE, Clotilde Matta e Silva foi homenageada em razão de sua morte, pelo professor Carlos Sá (1954, p. 40), na Revista Educação na seção "Página de Saudade". O professor trata de seus valiosos e intensos trabalhos na Associação Brasileira de Educação:

\begin{abstract}
Quem compulsar os arquivos da ABE raramente encontrará o seu nome em pareceres ou moções apresentadas ao Conselho Diretor ou a conferências educacionais. O seu papel, como o de outras abnegadas professoras e consocias, foi mais discreto, e nem por isto menos eficiente. Ela cooperava devotadamente nos trabalhos silenciosos de organização, quer se tratasse de preparar um congresso nacional de educadores, quer de uma simples recepção [...].
\end{abstract}

Uma das primeiras secretárias da $A B E$, Juracy Silveira, colaboradora fiel de Anísio Teixeira, foi uma ativa participante das atividades da associação, onde havia um forte grupo que discutia as propostas levadas por Anísio à frente da Diretoria da Instrução Pública.

Do grupo de professores selecionados pela ABE para viajar aos Estados Unidos, excetuando os professores de São Paulo, todos os outros pertenciam aos seus quadros, fossem como sócios, atuando na secretaria, na coordenação das Sessões, no Conselho Diretor, na presidência ou organizando atividades. Exem- plos disso é Carlos Delgado de Carvalho, que foi vice-presidente e Décio Lyra da Silva, secretário.

Laura Lacombe, conforme observa Caruso (2006), uma destacada sócia, integrou o grupo que se reunia na $A B E$, com a finalidade de discutir a implantação da educação renovada nas instituições de ensino do país. Ao ocupar esse espaço, congregado por setores da intelectualidade, Laura Lacombe conquistou maior visibilidade e compartilhou de uma visão de mundo semelhante à de seus interlocutores, que experimentavam grande prestígio naquele momento da ABE.

Esses viajantes estavam envolvidos em um grupo específico, que se colocou como os agentes responsáveis por direcionarem os rumos da educação brasileira. Eles foram favorecidos pelas relações sociais que estabeleceram na $A B E$ ou na administração do ensino público, na capital carioca, facilitando sua atuação, enquanto agentes responsáveis por aprender e se especializar, e passando a deter um saber específico, obtido nos Estados Unidos. Quando voltavam da viagem, iriam discutir, debater, escrever, publicar e ocupar posições estratégicas no campo educacional brasileiro.

Entendemos, assim, que os professores selecionados não se formaram isoladamente da sociedade da qual faziam parte. Sempre, de algum modo, estiveram ligados a grupos e pessoas que os legitimavam e os tomavam com referências para escrever e pensar o mundo em que viviam, sobretudo o campo educacional. Partilhavam, ainda, de objetivos e ideias comuns; obrigações e conexões sociais; relações de conhecimento e reconhecimento mútuo; do estabelecimento de acordos e regras nas questões a serem debatidas e que depois seriam tratadas em âmbito social.

Além de pertencer a um grupo específico, eram necessários alguns critérios para viajar. A professora Julieta Arruda, que foi uma das se- 
lecionadas pela $\mathrm{ABE}$, relatou ao jornal Correio da Manhã, ${ }^{2}$ as condições de seleção para a viagem de estudos aos Estados Unidos: “[...] Eram condições essenciais para a inscripção: falar inglez, ter-se distinguido em trabalhos pedagógicos, ter um assumpto a estudar e estar em condições de pagar sua passagem".

No arquivo pessoal de Anísio Teixeira, sob a guarda do CPDOC, foi possivel encontrar oficios, totalizando-se cinco (5), que tratam da viagem de professores do antigo Distrito Federal, que partiriam em missão educativa nos Estados Unidos. 0 ofício de número 398, de 07 de junho de 1932 encaminhado por Anísio Teixeira a Pedro Ernesto Batista, trata da seleção dos candidatos. Alguns critérios eram fundamentais para a aprovação: compreender o inglês, demonstrar capacidade intelectual e ter aprovação nas provas aplicadas para este fim.

Compreende-se, então, que os selecionados, os eleitos para a viagem de estudos já estavam dentro de situações de privilégio. Possuíam capitais culturais acumulados e diversificados, em virtude do saber, da competência, das relações sociais, de disposições e interesses semelhantes, questões estas que poderiam ser decisórias no processo seletivo.

\section{A relação do Brasil com os}

\section{Estados Unidos e os percursos da viagem}

Qual a relação do Brasil com os Estados Unidos? Por que esse país se torna o destino privilegiado nas viagens de estudo? Como foi o percurso da viagem? Quais instituições educativas foram visitadas?

Ao longo dos séculos XIX e XX, os Estados Unidos vinham criando uma série de estratégias para firmar relações, não somente com o Brasil, mas com toda a América Latina, no in-

2 IEB, arquivo Fernando de Azevedo, recorte do jornal Correio da Manhã, 27/03/1930. tuito de "impor" um modelo de sociedade, de ideologia, de política, de economia, de cultura e de educação.

Vieira (2006, p. 105) observa que, embora se considere o século XIX como predominantemente inglês, principalmente no que tange ao domínio econômico por parte da Inglaterra sobre o Brasil, após o tratado do comércio e navegação, firmado entre Portugal e Inglaterra, em 19 de fevereiro de 1879, pode-se dizer que a segunda metade do século XIX representa, em termos mundiais, um período de transformação profunda no panorama sociopolítico e econômico, e, em termos hemisféricos, corresponde ao início da política imperialista norte-americana, em nível mundial, e à inclusão da América Latina no seu sistema de poder em formação, desbancando a hegemonia inglesa na condução dos novos rumos do capitalismo mercantil.

A América do Norte, enquanto modelo alternativo à vida social e política brasileira, está presente desde a segunda metade do século $\mathrm{XIX}$, no período que a história consagrou como Segundo Reinado. Além disso, o Império brasileiro apoiou a Doutrina Monroe, em 1824, após o reconhecimento da independência do Brasil pelo governo norte-americano, que não queria para o Brasil o apoio de um país europeu.

Foi ainda na década de 1870 que os Estados Unidos começaram a ser tomados como o país que possuía um dos sistemas de ensino mais sólido e amplamente distribuído pela população, razão pela qual estava sendo apontado como uma das referências para a instrução no Brasil. Nesse movimento, ao lado de países como a França, Alemanha, Inglaterra, Bélgica, Áustria, Holanda e Suiça, os Estados Unidos da América do Norte começavam a aparecer como um modelo a ser seguido. Paulatinamente, esse país foi se constituindo em um paradigma para o campo educacional brasileiro, em um processo que, pouco a pouco, provocaria 
o deslocamento de alguns países europeus, como a França, por exemplo, em sua posição de prestígio perante a elite intelectual brasileira (CHAMON, 2005).

Se as viagens pedagógicas aos Estados Unidos aconteciam ainda no período monárquico, com o alvorecer da república, elas se intensificam, já que esse país se torna modelo referencial, com suas técnicas e métodos educativos considerados inovadores. Assim, constituía um parâmetro, para professores e todos aqueles envolvidos com as questões educativas, conhecer o modelo educacional dos EUA.

É no período de 1929-1935 que Anísio Teixeira, enquanto diretor da Instrução Pública carioca, e a Associação Brasileira de Educação apoiam e financiam viagens, aos Estados Unidos, para um grupo de professores do Rio de Janeiro e São Paulo estudar em suas universidades e conhecer o seu modelo de educação.

Como teria sido a experiência de entrar em contato com uma cultura escolar considerada moderna, ao visitar as escolas, as instituições educacionais do país, então idealizado como símbolo de progresso, da civilização, e da tão desejada modernidade pedagógica para a educação brasileira?

Os professores brasileiros mostraram-se satisfeitos com tudo o que ocorrera na viagem, desde a partida até a chegada, e tudo o que foi possivel conhecer e visitar no pais estrangeiro. Escrevem, concedem entrevistas sobre a recepção dispensada, que inclui trocas de presentes, chás, almoços, jantares, passeios, lazer, diversão. Traduzem o entusiasmo do que lhes foi possivel observar e vivenciar. Em entrevista ao jornal "Correio da Manhã", a professora Julieta Martins Arruda trata da partida, da chegada e da hospedagem:

A Companhia Munson Line offereceu grande reducção nos preços e um tratamento especial à bordo. Partimos do Rio a 1o de janeiro, chegan- do a Nova York a 14. Hospedaram-nos junto à Universidade de Colombia. ${ }^{3}$

Do mesmo modo, Laura Jacobina Lacombe, em seu relatório "Cinco semanas nos Estados Unidos", publicado na Revista Schola, inicia a sua escrita tratando da viagem: partida, chegada, custeio de hospedagem, organização do programa:

A bordo do American Legion, partimos a 1‥ De janeiro; constituímos a primeira delegação que a Associação brasileira de Educação enviou aos Estados Unidos. Constava essa delegação de dez professores, sendo oito escolhidos pelo conselho director da A.B.E. e três enviadas pelo governo de São Paulo. A estadia na America do Norte foi custeada pela Carnegie Endowment e o programa foi cuidadosamente organizado pelo Institute of International Education. ${ }^{4}$

Maria Junqueira Schmidt, que viajou juntamente com a professora Aracy Muniz Freire, aos Estados Unidos, em 1934, escreve a Anísio Teixeira, a bordo da companhia Munson Steamship Lines. A remetente apresenta-se satisfeitíssima com a viagem, agradece ao diretor o apoio recebido, conta-lhe o transcurso da viagem e os planos para o futuro, ao chegar a Nova Iorque:

Desde o momento em que me vi a bordo cresceu ainda mais a minha gratidão pela sua manifesta boa vontade em me proporcionar esta viagem maravilhosa! A tantas attenções, juntase mais esta agora para avolumar o meu reconhecimento pelo senhor. A nossa viagem não podia ser mais agradável: o mar sempre calmo, pouca gente e muito socego. ${ }^{5}$

3 IEB, arquivo Fernando de Azevedo, recorte do jornal o Correio da Manhã. "Procurando solucionar o problema educacional no Brasil" (rápida palestra com a professora d. Julieta Arruda sobre o curso de férias no Instituto de E.I. de Nova York), Rio de Janeiro, 27/03/1930.

4 Revista Schola, ano 1, n. 3, p. 90-96, mar. 1930.

5 Carta de Maria Junqueira Schmidt a Anísio Teixeira. Classificação: AT c 1934.10.18. Série: c - Correspondência. Quantidade de documentos: 1 (3 folhas). Microfilmagem: rolo 37 fot. 778. Arquivo: Anísio Teixeira (AT). CPDOC/FGV/RJ. Data de produção: 18/10/1934. 
As visitas de estudo às escolas foram experiências significantes para os viajantes, pois dificilmente há em seus relatos comentários negativos. Quando há, são apenas pequenos detalhes de uma escola que não tinha iluminação suficiente, mas que isso poderia ser facilmente resolvido, como observa Décio Lyra da Silva. Ou uma escola e outra que ainda se baseava nos moldes tradicionais da educação, sobretudo nas escolas em áreas rurais, como diz Maria dos Reis Campos.

Os professores viajantes apresentam-se satisfeitos com tudo o que puderam presenciar. Um exemplo é Laura Lacombe, que, em seu relato, se mostra admirada com uma das escolas visitadas: "Baltimore City College é quase um castelo. A Escola Normal mais magnificiente que tenho visto até hoje. A Escola Normal encantou-me pela sua diretora, Miss Tall, com quem pude ter longa palestra" (LACOMBE, 1930, p. 95).

A professora Maria dos Reis Campos também escreve sobre a sua admiração pelas escolas norte-americanas: "as escolas americanas são palácios, onde o luxo é substituído pelo conforto e onde se prepara, em ambiente de alegria sã, a geração futura". ${ }^{6}$ Já Consuelo Pinheiro diz que a escola americana funciona perfeitamente devido às atividades extracurriculares e os clubes: "Em todas as escolas há clubes de geographia, de arithimetica, de sciencias, dos amigos da escola, etc., que despertam nas crianças o habito da discussão".

No geral, as instituições educativas visitadas são apresentadas nos relatos como excelentes, surpreendentes, interessantes, efica-

6 IEB, arquivo Fernando de Azevedo, recorte do jornal Diário Carioca, 07/03/1930. Entrevista com a professora Maria dos Campos Reis: "O regresso da delegação da Associação Brasileira de Educação - o que disseram ao Diário Carioca o seu chefe e a professora Maria dos Campos Reis.

7 IEB, arquivo Fernando de Azevedo, recorte do jornal Diário da Noite, 11/03/1930. Entrevista com a professora Maria dos Reis Campos e Consuelo Pinheiro: "Os novos methodos de ensino americano no Brasil". zes, modernas. Nas escolas, há toda uma diversidade de materiais didáticos e os professores estão bem preparados para exercer o seu oficio, com a utilização dos métodos e técnicas modernos que os auxiliam no ato de ensinar e aprender. 0 que chama a atenção também é que os alunos são sujeitos de sua aprendizagem e o professor não é o detentor do saber, mais um amigo, um mediador, sempre pronto a auxiliar e guiar os seus discípulos.

De todas as escolas visitadas por esses professores, a Lincoln School destaca-se, não só por ser uma escola experimental, mas por ter um corpo de professores especializados e preparados para as questões do ensino e da aprendizagem. Ela é modelo para todas as outras, nos Estados Unidos. De acordo com a professora Consuelo Pinheiro, "a influencia da Lincoln School estende-se a todos os Estados Unidos e é grande a affluencia de professores vindos de vários pontos para assistir-lhes as aulas". 8 A professora finaliza seu relato dizendo que ficou muito satisfeita com os trabalhos educativos realizados nessa escola.

Décio Lyra comenta da “impressão maraviIhosa que the deixou a visita que fez aos estabelecimentos de ensino, da República de Tio Sam, bem como o acolhimento que a todos os membros da embaixada foi dispensado". ${ }^{9}$ Já Maria dos Reis Campos diz, no final de seu relatório, publicado na Revista Schola, ${ }^{10}$ que não poderia deixar de "consignar os mais calorosos applausos à obra de alto patriotismo, em que se empenham o Institute of International Education, the Carnegie Foundation e outras instituições americanas, que em combinação com a nossa A.B.E. organizaram estes tão productivos imtercambios de professores norte -americanos e brasileiros".

8 Idem.

9 IEB, arquivo Fernando de Azevedo, recorte do jornal A Ordem, 11/03/1930.

10 Revista Schola, Rio de Janeiro, ano 1, n. 6, p. 179-182, jul. 1930. 


\section{Especialistas em novos campos} de saberes

Chegando ao seu destino, os professores viajantes eram encaminhados para as instituições de ensino, escolhidas ou encarregadas. lam estudar determinado assunto: organização universitária, orientação profissional, ensino primário, orientação educacional, educação musical, educação sanitária, métodos de ensino, ensino de física, química, dentre outros.

O TC $^{11}$ foi a instituição privilegiada para uma formação especializada. Estudar e ter um diploma do TC teve um peso importante no percurso profissional dos professores viajantes, tanto pelo que significou de oportunidade de aprendizagem, quanto pelo que representou na aquisição de conhecimentos, nos campos da pedagogia, da sociologia, da filosofia, da psicologia e das inovações didáticas e metodológicas.

Consuelo Pinheiro, Maria Reis Campos e Laura Lacombe estudaram métodos de projetos. A professora Julieta Arruda estudou a educação sexual e a estrutura e organização da educação norte-americana. Décio Lyra da Silva, o ensino profissional, o ensino da física e da química, no entanto, o que se encontra em seus relatos é sobre a educação americana, de um modo geral. "Organização universi-

11 Localizado na cidade de Nova York, o Teachers College, a maior e mais antiga escola de pós-graduação em Educação dos Estados Unidos, fundada em 1894, foi construído devido à doação de um milhão de dólares feita por John D. Rockefeller Jr. De acordo com Barbosa (2014), dentre os fundadores do TC estão a filantropista e feminista Grace Hoadley Dodge; o filósofo e estudioso de educação, Nicholas Murray Butler, defensor do preparo mais adequado para professores; 0 reformador da educação e designer da educação profissional, James E. Russell, este assumiu o papel de primeiro Diretor do Teachers College. A criação dessa instituição evoluiu de um processo iniciado e liderado por Grace Dodge, que criou a Working Girls Society; a YWCA (Young Women's Christian Association); a Travelers Aid para expansão da cultura e proteção das mulheres pobres; e finalmente a Industrial Education Association (IEA), que rapidamente se transformou no New York College for the Training of Teachers e depois Teachers College. tária", este foi o assunto que Couto e Silva e Othon Leonardos estudaram. Carolina Rangel e Eunice Caldas estudaram educação sanitária. Celina Padilha, a educação norte-americana e as instituições de ensino primário. Aracy Muniz Freire estudou orientação educacional; Maria dos reis Campos, a escola moderna; Ceição de Barros Barreto, a educação musical; Noemy da Silveira Rudolfer, psicologia educacional e Maria Junqueira Schmidt, orientação educacional e ensino de línguas. Faremos uma análise dos livros publicados por essas professoras, pois estão relacionados diretamente a suas viagens de estudo.

No grupo de viajantes, além de ser a maioria, é significativa a participação das mulheres como autoras de livros. Elas tiveram uma produção significativa referente às suas viagens de estudo, contribuindo, assim, para os debates em torno do campo educacional. Produziram livros sobre o que estudaram nos Estados Unidos, e ainda relataram as experiências realizadas, quando atuaram nas escolas do antigo Distrito Federal.

Envolvidas com as questões da instrução e do ofício docente, do ensino primário, da orientação educacional, da psicologia educacional, do ensino de línguas, das metodologias de ensino, discutiram o que consideraram os principais problemas enfrentados à sua época e suas possíveis soluções.

Dos conhecimentos adquiridos nos Estados Unidos e reapropriados, produziram uma escrita propondo ideias novas para a área na qual se especializaram, sendo mesmo algumas pioneiras no assunto. A partir de suas contribuições e da divulgação de saberes e teorias conhecidos em terras norte-americanas, tiveram um importante papel na ampliação de novos campos de conhecimento, de organização do ensino e novas formas de ensinar e aprender.

Os professores viajantes também tiveram uma produção significativa. No entanto, foram 
Aracy Muniz Freire, Maria dos Reis Campos, Ceição de Barros Barreto, Noemy da Silveira Rudolfer e Maria Junqueira Schmidt que se tornaram especialistas em novos campos do saber.

Aracy Muniz Freire tornou-se uma especialista em orientação educacional. Muitos autores, como por exemplo, Lourenço Filho, escreveram sobre o tema orientação educacional, mas a professora Aracy Muniz Freire foi a pioneira, pesquisando, estudando e escrevendo sobre esse assunto, e contribuindo, assim, para um novo campo de conhecimento. Um fruto dos seus estudos foi a publicação do livro "A orientação educacional na Escola Secundária" (FREIRE, 1940).

Esse livro tem duas partes distintas. Na primeira, a autora aborda teoricamente a Orientação Educacional, em termos de necessidade, de métodos, de técnicas e pré-requisitos para a função de orientador educacional. Na segunda parte, trata da experiência realizada por ela mesma, como orientadora educacional, na Escola Amaro Cavalcante, no Rio de Janeiro. A obra apresenta um modelo de Serviço de Orientação Educacional para a escola secundária.

O livro foi prefaciado por Delgado de Carvalho (1940), que fez elogios e, ao mesmo tempo, demonstrou como a professora Aracy Muniz Freire tornou-se especialista no assunto, estudando com vários professores renomados, no Teachers College.

Maria dos Reis Campos escreveu sobre a escola moderna, a Escola Nova, sobre leitura e escrita, escola primária, método de projetos, dentre outros assuntos. A autora publicou uma importante obra: Escola moderna: conceitos $e$ práticas. No prefácio, ela diz que esse livro resultou de sua viagem aos Estados Unidos, em 1929. O livro teve uma segunda edição, no ano de 1936 (CAMPOS, 1936).

A obra contém 318 páginas e está organi- zada em nove capítulos: 1. Evolução da Escola Elementar; 2. Precursores e iniciadores da Escola Moderna; 3. Aspectos da psychologia infantil; 4. Principaes caracteristicas da Escola Moderna: finalidades e princípios basicos; 5 . Principaes caracteristicas da Escola Moderna: organização; 6. Principaes caracteristicas da Escola Moderna: o methodo; 7. O professor; 8. Meios auxiliares do ensino; 9. A escola moderna no Brasil.

Ceição de Barros Barreto especializou-se no ensino de música, sobretudo canto orfeônico. Ela produziu um importante livro relacionado à educação musical: “Côro Orfeão", prefaciado por Lourenço Filho. Examina como o ensino de música é adotado nas escolas e os resultados obtidos. Observa que, quando mal-empregado, os seus efeitos são negativos na formação do gosto estético pelo ensino da música. Demonstra como o canto pode motivar um maior desejo de conhecimento da teoria musical, e, quando bem-empregado, suscita o desejo de conhecer a teoria gramatical.

Em “Coro Orfeão" (BARRETO, 1938), a autora utiliza uma bibliografia nacional e internacional, títulos publicados em francês, inglês, espanhol, italiano e português, do Brasil e de Portugal. São relatadas experiências inovadoras de aprendizagem em educação musical.

Noemy Silveira Rudolfer teve uma produção significativa sobre o tema psicologia educacional. Ela observa que foi a primeira visita aos Estados Unidos que “incentivou o desejo de especializar-se em Psicologia". Em 1938, publicou o livro: Introducção à Psychologia educacional (RUDOLFER, 1938). No prefácio, a autora diz que pretendeu fazer uma revisão da história da Psicologia, incluindo a sua evolução educacional. Em 1960, na segunda edição, o título é modificado para Introdução à psicologia educacional. No capítulo final, há a inclusão de cinco modernas teorias de aprendizagem: teoria dos estímulos, de E. R. Guthrie; teoria do 
condicionamento, de Clark Hull; teoria de campo, de Kurt Lewin; teoria organísmica da aprendizagem, de Wheeler; teoria da aprendizagem com um propósito e o comportamento molar de Tolman. 0 livro contém 20 capítulos, relata pormenores da história da Psicologia, desde sua origem até os novos desenvolvimentos das teorias modernas da aprendizagem.

Maria Junqueira Schmidt escreveu sobre muitos assuntos, sobretudo orientação educacional, ensino de línguas e literatura. A autora escreveu um importante livro sobre o tema ensino de línguas estrangeiras, tema bastante estudado em seus intercâmbios culturais. "O ensino científico das línguas modernas" (SCHMIDT, 1935) inaugura a era de publicações sobre o ensino formal e a aprendizagem de línguas. Dividido em 13 capítulos, a obra apresenta sugestões para inserir o ensino de línguas estrangeiras no currículo escolar; como se ensinar línguas cientificamente; como avaliar a aprendizagem de línguas; como elaborar planos de aula e lições. Tudo isso sempre tomando como exemplo o que já tinha sido feito fora do Brasil, anteriormente, na Europa e nos Estados Unidos.

A produção dessas professoras aliavase à produção de um lugar: o de especialista (CHAMON, 2005). Da viagem realizada, voltaram como especialistas, o que permitia a elas intervir no debate público e propor caminhos para uma escolarização mais eficaz, por meio de seus livros.

Segundo Jorge Nagle (2001, p. 338), a partir da década de 1920, começou a aparecer o educador como teorizador da educação. Assim, os assuntos educacionais passaram a ser tratados por um grupo definido de intelectuais, que adquiriam qualificação especializada, "e não mais, como era corrente, pelos intelectuais em geral ou pelos homens públicos, homens de letras, jornalistas, especialmente os representantes públicos".
No campo da educação, as mulheres tiveram uma importante participação na produção do conhecimento. Apesar de serem atuantes no fazer histórico, suas vozes foram silenciadas (POLLAK, 1989). Atuaram em um campo onde havia disputas de interesses políticos e pedagógicos (MORAES, 2008), e nessa disputa sobressaiu a visão e a voz masculina dos ideólogos da Escola Nova.

Não iremos discutir a questão de gênero, mas é importante ressaltar que muitas mulheres se destacaram no campo do conhecimento, conquistaram novos espaços e extrapolaram os limites domésticos. Dessa forma, se torna importante tratar da mulher como produtora de um saber especializado, pois os registros mais tradicionais minimizaram ou ignoraram a sua contribuição, nas mais diversas áreas.

\section{Os relatos das experiências educativas estrangeiras}

De volta de suas viagens de estudo, os professores deveriam produzir um documento que atestassem as suas visitas aos países estrangeiros. 0 exercício da escrita era uma das obrigações do viajante, no desígnio de divulgar o que aprendera. Chamon e Faria Filho (2007, p. 56) observam que, na trajetória de muitos viajantes, a escrita se mostrou inseparável da viagem. "A escrita atitude reflexiva transposta para o papel, é o momento privilegiado de apresentar ao seu país o outro visitado".

Os relatos dos viajantes podem ser caracterizados como uma "prática discursiva produtora de mediações culturais, cujos efeitos aparecem nas estratégias de apropriação de determinadas ideias, conceitos e modelos e na recusa explícita, no silenciamento ou no esquecimento de outros" (SCHUELER, 2007, p. 107).

As experiências dos professores viajantes foram transformadas em relatos, alguns produzidos e entregues a autoridades e órgãos 
oficiais. Algumas dessas experiências foram narradas em cartas enviadas a amigos e ocupantes de cargos administrativos na esfera pública. E outras, principalmente, foram publicadas nos jornais e revistas, na pretensão de dar visibilidade às iniciativas educacionais que ocorriam mundo afora.

A Revista Schola, logo depois transformada em Revista Educação, ambas editadas pela $A B E$, sempre traziam relatos de viagem, sobretudo dos professores que partiram, em missão de estudos, para os Estados Unidos. A publicação nessas revistas fica evidente, pois a $A B E$ financiou viagens para professores, e ainda estava envolvida no projeto de sistematização e desenvolvimento da educação nacional. Logo, os professores deveriam publicar os resultados de suas experiências.

Compreendemos que a publicação desses relatos de viagens estava relacionada a projetos editoriais da Revista Schola e da Revista Educação, que pretendiam apresentar, dar visibilidade e fazer circular as iniciativas educacionais estrangeiras.

No geral, os relatos apresentavam estudos sobre as características físicas das escolas visitadas; como os seus espaços (salas de aulas, laboratórios, gabinetes, ginásios, pátios etc.); os programas escolares; a formação de professores; questões relativas aos métodos e sistemas de ensino; questões teóricas, sociais, psicológicas, entre outras, fazendo notar o seu caráter bastante amplo.

Nos escritos de viagem, o olhar se apropria do factual e constrói uma nova realidade, pois, ao serem produzidos, serviram, primeiramente, aos interesses dos grupos sociais aos quais estavam diretamente ligados. No caso dos viajantes desse estudo, à Diretoria Geral da Instrução Pública do Rio de Janeiro e à Associação Brasileira de Educação, já que estavam envolvidos com a reforma do ensino público. É a partir das experiências escritas por esses professores que será possivel às esferas governamentais pensar políticas para a educação, a formação dos professores, bem como em formas de ensinar e aprender, ou sobre a organização de espaços escolares, metodologias etc.

De suas visitas de estudo aos Estados Unidos, Noemi Silveira Rudolfer (1930) apresenta em à $A B E$ um detalhado relatório de viagem, logo publicado no jornal O Estado de São Paulo e na Revista Educação da Diretoria Geral do Ensino de São Paulo. Noemy da Silveira Rudolfer também ministrou uma série de palestras, que foram publicadas, relatando a vida intelectual nos Estados Unidos da América e tratando das impressões de sua viagem.

O jornal Correio da Manhã publica, em $12 / 04 / 1930$, uma parte do relatório da professora Julieta Arruda, que já havia sido entregue à Associação Brasileira de Educação. De acordo com o referido jornal, o relatório é um trabalho "longo e minucioso, em que estuda os vários problemas que se prendem ao ensino, deixando claros os methodos adotados na América do Norte, para a melhor difusão dos conhecimentos necessários à vida moderna".12

Ceição de Barros Barreto apresentou, ao Ministério da Educação, um relatório de suas visitas às instituições norte-americanas, para verificar como é realizado o ensino de educação musical. Esse relatório foi publicado na Revista Educação.13 A professora Ceição, além das visitas às universidades, visitou escolas primárias e secundárias. Dessas visitas há uma informação na Revista Educação:

Nas visitas a diversos dêstes estabelecimentos e Escolas teve a Professora Ceição de Barros Barreto oportunidade de acompanhar vários cursos, participar de trabalhos e discussões em

12 IEB, arquivo Fernando de Azevedo, recorte do jornal Correio da Manhã. "O problema educacional e os cursos de férias nos Estados Unidos", Rio de Janeiro, $12 / 04 / 1930$.

13 Revista Educação, Rio de Janeiro, n. 12, p. 7-10, out. 1941. 
côro, observando assim a orientação e os vários aspectos da educação artistica musical. ${ }^{14}$

Maria dos Reis Campos publicou, no Boletim de Educação Pública, ${ }^{15}$ um primeiro relatório de sua viagem de estudos aos Estados Unidos, sob o título "A educação primária nos Estados Unidos". Ela conta as experiências vividas, as escolas observadas, que se caracterizam por um novo modelo de educação, ou seja, a "escola nova". A viajante também publicou na Revista Schola ${ }^{16}$ o estudo realizado nas escolas norte-americanas sobre o método de projetos.

Laura Lacombe publicou seu relatório de viagem na Revista Schola, sob o título "Cinco semanas nos Estados Unidos"." Ela descreve o percurso da viagem, a chegada, a recepção, os professores que foram selecionados, as suas experiências no campo educacional, as cidades e escolas visitadas, as características físicas, a metodologia e os trabalhos realizados. Laura Lacombe publicou também as suas experiências de estudo no Teachers College, e as observações realizadas na escola primária Lincoln School e na escola secundária Horace Mann School..$^{18}$ A professora Laura Lacombe faz algumas reflexões sobre o ensino nos Estados Unidos:

O relatório de Consuelo Pinheiro, apresentado ao Conselho Diretor da Associação Brasileira de Educação, quando do regresso de sua viagem aos Estados Unidos, também foi publicado na Revista Schola. A relatora descreve as cidades e escolas visitadas e faz reflexões sobre a grandeza da educação norte-americana, bem como de sua sociedade e cultura.

Os impressos são espaços privilegiados de escrita para a defesa de crenças e formação

\footnotetext{
14 Idem, p. 7.
}

15 Boletim de Educação Pública, Rio de Janeiro, v. 1, n. 3, p. 381-393, 1930.

16 Revista Schola, Rio de Janeiro, ano 1, n. 6, p. 179-182, jul. 1930.

17 Revista Schola, ano 1, n. 3, p. 90-96, mar. 1930.

18 Revista Schola, ano 1, n. 6, p. 183-187, jul. 1930. de opinião. Em suas páginas, os professores viajantes apresentavam um conjunto de diagnósticos, na pretensão de refletir sobre os problemas educacionais brasileiros e propor medidas para a organização do campo. E, além disso, exaltar a educação norte-americana.

Consuelo Pinheiro diz ter visitado escolas, nos Estados Unidos, "em que as mais interessantes experiências estão sendo feitas para a formação de uma humanidade melhor e mais feliz" (1930, p. 169). Segundo Julieta Arruda, “a educação na América repousa sobre três grandes alicerces: - o amor pela criança, o sentimento da democracia e a compreensão de que uma nova civilização precisa de uma nova philosophia educativa". ${ }^{9}$

Os métodos de ensino, os materiais didáticos e a formação do professor também eram recorrentes nos relatos. A professora Maria dos Reis Campos, em visita às escolas norte-americanas, ficou muito impressionada e admirada com o que presenciara:

Foi profunda a impressão que tive das escolas americanas. A par dos methodos novos, applicados com intelligencia, admirei a grandeza das installações, com a sua adaptabilidade perfeita ao fim destinado. Riqueza de apparelhamento, abundancia de livros e material, professores optimamente treinados e cheios de enthusiasmo pela obra a que se dedicam. ${ }^{20}$

Consuelo Pinheiro diz que as escolas norte-americanas “impressionaram pelos grandes terrenos que possuem, magnificas salas, todas espaçosas, bem illuminadas e arejadas, ricas e variadas bibliothecas infantis". ${ }^{21}$ Ceição de Barros diz que a educação musical, nas escolas elementares americanas, "basea-se, geralmente, no estudo prévio e na observação

19 IEB, arquivo Fernando de Azevedo, recorte do jornal Correio da Manhã. Rio de Janeiro, 12/04/1930.

20 IEB, arquivo Fernando de Azevedo, recorte do jornal A Ordem. "Como os Estados Unidos resolvem o problema do ensino", Rio de Janeiro, 11/03/1930.

21 IEB, arquivo Fernando de Azevedo, recorte do jornal 0 Globo. "O estudo directo dos mais modernos processos de ensino", Rio de Janeiro, 11/03/1930. 
da criança" (1935, p. 7). Seus interesses, suas possibilidades, suas aptidões, são habilmente orientadas por meio da música, em seu próprio benefício, no da coletividade e, assim, da própria arte. 0 professor Décio da Lyra diz que, nas escolas americanas visitadas, os "methodos novos são applicados com maior ou menor amplidão, seguindo esta ou aquella modalidade, mas sempre com um norteamento bem entendido, sempre visando o desenvolvimento da iniciativa, o fortalecimento do caracter".22 Já a professora Consuelo Pinheiro faz a seguinte reflexão: "na America do Norte as exigencias impostas pela industrialisação sempre crescente, são de tal ordem, que não basta a escola tradicional e formalistica, onde se aprende a lêr, escrever e contar. É preciso mais".23

A publicação dos relatos de viagem, seja nas revistas Schola, Educação (do Rio de Janeiro), Educação (de São Paulo), Boletim de Educação Pública ou nos jornais (O Globo, O Dia, A Noite, A Tarde, dentre outros), começava a desempenhar um papel significativo na produção de saberes ligados à educação. Por suas páginas, a educação passava não só a ser vista como um problema social, mas como tendo papel estratégico na superação do atraso e na promoção do progresso no Brasil, seguindo diretrizes de modelos educacionais estrangeiros. "Entende-se que as Revistas, ao mesmo tempo que veicularam um discurso pedagógico, ajudaram, de forma decisiva, a produzi-lo" (FERNANDES, 2010, p. 107).

Os impressos também foram importantes para dar visibilidade à produção escrita dos professores viajantes. Sobre essa questão Nóvoa (2002) diz ser necessário considerar o poder que os periódicos possuem de demo-

22 IEB, arquivo Fernando de Azevedo, recorte do jornal Diário Carioca. "Uma visão intelligente dos Estados Unidos", Rio de Janeiro, 07/03/1930.

23 IEB, arquivo Fernando de Azevedo, recorte do jornal 0 Globo. "O estudo directo dos mais modernos processos de ensino", Rio de Janeiro, 11/03/1930. cratizar o acesso ao conhecimento e também compreender a importância que eles têm para fazer circular novos autores.

\section{Considerações finais}

Essas viagens foram relevantes, no sentido de permitirem a troca de experiências pedagógicas e o aperfeiçoamento de uma área específica de atuação, projetos educativos, disciplinas ou grau de ensino. E ainda importantes experiências para os viajantes compreenderem melhor a sua realidade, a partir da realidade do outro.

Depois de suas viagens aos Estados Unidos, os professores brasileiros tiveram a oportunidade de atuar mais intensamente na área educacional, recebendo vários convites, por razões do conhecimento in loco adquirido no país estrangeiro, o que lhes permitiu um lugar de prestígio no campo educacional. Em razão disso, alguns ocuparam cargos de poder. Os capitais acumulados e adquiridos com os conhecimentos específicos de um campo conferiam a eles poder, reservando-lhes o direito de estar à frente das questões e decisões educacionais.

Conhecer de perto a realidade de lugares considerados como mais "civilizados", referências em matéria de difusão, métodos e organização escolar, poderia significar a apropriação de experiências e instrumentos para o enfrentamento das dificuldades que os reformadores encontravam para realizar, nos seus países de origem, uma reforma educacional.

Anísio Teixeira juntamente com a ABE empenhou-se em difundir no Brasil os avanços no campo da educação em vigor nos Estados Unidos, ocupando ambos papéis de mediadores de uma cultura educacional norte-americana. Investindo em viagens pedagógicas, a associação e o diretor da Instrução Pública tinham como finalidade contribuir para o aperfeiçoa- 
mento do sistema educacional, como de seu professorado; a difusão de métodos de ensino, técnicas consideradas inovadoras e experiências educativas estrangeiras que viessem a cooperar com o trabalho docente e discente, e a valorização das iniciativas que viessem ao encontro desses objetivos.

Além disso, os professores viajantes seriam mediadores de uma cultura pedagógica valorizada naquele momento. Seriam, também, os representantes e divulgadores de determinado modelo educacional, de padrão de escola e de ensino. Transmitiriam informações de uma

\section{Referências}

BARBOSA, Ana Mae Tavares Bastos. O Teachers College e sua influência na modernização da educação no Brasil. Revista Arte. V. 1, N. 1, p. 7-30, 2014.

BARRETO, Ceição de Barros. Côro Orfeão. São Paulo: Companhia Melhoramentos; Rio de Janeiro: Caieiras, 1938.

BARRETO, Ceição de Barros. O ensino artístico e musical nos Estados Unidos. Revista Educação, Rio de Janeiro, n. 12, p. 7, out. 1935.

CAMPOS, Maria dos Reis. Escola moderna: conceitos e práticas. 2. ed. Rio de Janeiro: Livraria Francisco Alves, 1936.

CARUSO, Andrea. Traço de união como vitrine: educação feminina, ideário católico e práticas escolanovistas no periódico do Colégio Jacobina. 2006. 231 f. Dissertação (Mestrado e Educação - Programa de Pós-Graduação da Universidade do Estado do Rio de Janeiro, Rio de Janeiro, 2006.

CARVALHO, Delgado. Prefácio. In: FREIRE, Aracy Muniz. A orientação educacional na escola secundária. São Paulo: Cia. Editora Nacional, 1940. p. 7-9.

CARVAlHo, Marta Maria Chagas. "A caixa de utensílios": o tratado e a biblioteca: pedagogia e práticas de leitura de professores. In: VIDAL, Diana Gonçalves; HISLDORF, Maria Lucia. (Orgs.). Brasil 500 anos: tópicas em história da educação. São Paulo: Editora da Universidade de São Paulo, 2001. p. 137-168. verdade que estava sendo construída, como boa e legitimadora do sistema educacional brasileiro.

A prática das viagens pedagógicas, sendo uma tradição cultural e formativa, foi um movimento ocorrido em vários países do mundo. Mignot e Gondra (2007) apresentam esse tipo de viagem como técnica de investigação e conhecimento, como prática de observar, experimentar, comparar e produzir conhecimentos sobre o outro e sobre si, transformando aquilo que se observa, em experiência significativa na trajetória de homens e mulheres.

CARVAlHo, Marta Maria Chagas. Por uma história cultural dos saberes pedagógicos. In: SOUZA, Cyntia Pereira de.; CATANI, Denice. (Orgs.). Práticas educativas, culturas escolares e profissão docente. São Paulo: Escrituras, 1998. p. 31-41.

CHAMON, Carla Simone. Maria Guilhermina Loureiro de Andrade: a trajetória profissional de uma educadora. 2005. 338 f. Tese (Doutorado em Educação) - Faculdade de Educação, Universidade Federal de Minas Gerais, Belo Horizonte, 2005.

CHAMON, Carla Simone; FARIA FILHO, Luciano. A educação como problema, a América como destino: a experiência de Maria Guilhermina. In: MIGNOT, Ana Chrystina Venâncio; GONDRA, José. (Orgs). Viagens pedagógicas. São Paulo: Cortez, 2007. p. 39-64.

FERNANDES, Ana Lúcia Cunha. Estabelecer a unidade moral e intelectual do professorado: a construção da profissão docente em revistas pedagógicas do Brasil e de Portugal no final do século XIX. Sísifo/Revista de Ciências da Educação, n. 11, p. 105-114, jan./abr. 2010.

FREIRE, Aracy Muniz. A orientação educacional na escola secundária. São Paulo: Cia. Editora Nacional, 1940.

LACOMBE, Laura. Cinco semanas nos Estados Unidos (Relatório de viagem). Revista Schola, Rio de Janeiro, ano 1, n. 3, p. 95, mar. 1930. 
MIGNOT, Ana Chrystina Venancio; SILVA, Alexandra Lima da. Tão longe, tão perto: escrita de si em relatórios de viagens. Educação em Revista, Belo Horizonte, v. 27, n. 1, p. 435-458, abr. 2011.

MIGNOT, Ana Chrystina Venancio; GONDRA, José Gonçalves. Viagens de educadores e circulação de modelos pedagógicos. In: MIGNOT, Ana Chrystina Venâncio; GONDRA, José. (Orgs.). Viagens pedagógicas. São Paulo: Cortez, 2007. p. 7-14.

MORAES, Dislane Zerbinatti. Professores-escritores e suas práticas simbólicas de escrita ficcional: o estudo do jogo discursivo efetuado entre os campos educacional, intelectual e literário. In: LEITE, Juçara; ALVES, Claudia. (Orgs.). Intelectuais e história da educação no Brasil: poder, cultura e políticas. Vitória: EDUFES, 2011. p. 245-271.

MORAES, Dislane Zerbinatti. Ficções, memórias e culturas da escola: a escrita de "si", dos "outros" e da história da profissão docente. In: PASSEGI, Maria da Conceição; BARBOSA, Tatyana Mabel Nobre. (Orgs.). Narrativas de formação e saberes biográficos. Natal: EDUFRN; São Paulo: Paulus, 2008. p. 213229.

NAGLE, Jorge. Educação e sociedade na Primeira República. Rio de Janeiro: DP\&A, 2001.

NÓVOA, António. A imprensa de educação e ensino: concepção e organização do repertório português. In: CATANI, Denice Barbara; BASTOS, Maria Helena Câmara. (Orgs.). Educação em revista: a imprensa periódica e a história da educação. São Paulo: Escrituras, 2002. p. 11-31.

PIMENTA, Jussara Santos. As duas margens do Atlântico: um projeto de integração entre dois povos na viagem de Cecília Meireles (1934). 2008. 347 f. Tese (Doutorado em Educação) - Faculdade de Educação - Programa de Pós-graduação em Educação, Universidade do Estado do Rio de Janeiro, Rio de Janeiro, 2008.

PINHEIRO, Consuelo. A escola moderna (Relatório apresentado ao Conselho Diretor da A.B.E., quando do regresso de sua viagem aos Estados Unidos). Revista Schola, Rio de Janeiro, ano 1, n. 6, p. 169-175, jul. 1930.
POLLAK Michael. Memória, esquecimento, silêncio. Estudos Históricos, Rio de Janeiro, v. 2, n. 3, p. 3-15, 1989.

RUDOLFER, Noemi Marques da Silveira. Visitas de professores brasileiros aos Estados Unidos. Revista Educação. Órgão da Diretoria Geral da Instrução Pública e da Sociedade de Educação de São Paulo, São Paulo, v. XII. n. 1, p. 1-25, jan./fev. 1930.

RUDOLFER, Noemi Silveira. Introducção à psychologia educacional. São Paulo: Nacional, 1938.

SÁ, Carlos. Clotilde S. Matta. Revista Educação, Rio de Janeiro, n. 25, p. 40, mar. 1954.

SCHUELER, Alessandra Frota M. de. A longa peregrinação de um professor da roça na Europa. In: MIGNOT, Ana Chrystina Venâncio; GONDRA, José Gonçalves. (Orgs.). viagens pedagógicas. São Paulo: Cortez, 2007. p. 39-64.

SCHMIDT, M. 0 ensino científico das línguas modernas. Rio de Janeiro: Editora Briguiet \& Cia., 1935.

VIEIRA, Cesar Romero Amaral. Protestantismo e educação: a presença liberal norte-americana na reforma Caetano de Campos - 1890. 2006. 360 f. Tese (Doutorado em Educação) - Programa de PósGraduação em Educação, Universidade Metodista de Piracicaba, Piracicaba, 2006.

YGAYARA-SOUZA, Suzana Cecília Almeida. Entre palcos e páginas: a produção escrita por mulheres sobre música na história da educação musical no Brasil (1907-1958). 2011. 200 f. Tese (Doutorado em Educação) - Faculdade de Educação, Universidade de São Paulo, 2011.

\section{Fontes}

Boletim de Educação Pública, Rio de Janeiro, v. 1, n. 3, p. 381-393, 1930.

IEB, arquivo Fernando de Azevedo, recorte do jornal Correio da Manhã, 27/03/1930.

IEB, arquivo Fernando de Azevedo, recorte do jornal O Correio da Manhã. "Procurando solucionar o problema educacional no Brasil" (rápida palestra com a professora d. Julieta Arruda sobre o curso de fé- 
rias no Instituto de E.I. de Nova York), Rio de Janeiro, 27/03/1930.

\section{Carta de Maria Junqueira Schmidt a Anísio Teixeira.}

Classificação: AT c 1934.10.18. Série: c - Correspondência. Quantidade de documentos: 1 (3 f). Microfilmagem: rolo 37 fot. 778. Arquivo: Anísio Teixeira (AT). CPDOC/FGV/RJ. Data de produção: 18/10/1934

IEB, arquivo Fernando de Azevedo, recorte do jornal Diário Carioca, 07/03/1930. Entrevista com a professora Maria dos Campos Reis: "O regresso da delegação da Associação Brasileira de Educação - o que disseram ao Diário Carioca o seu chefe e a professora Maria dos Campos Reis.

IEB, arquivo Fernando de Azevedo, recorte do jornal Diário da Noite, 11/03/1930. Entrevista com a professora Maria dos Reis Campos e Consuelo Pinheiro: "Os novos methodos de ensino americano no Brasil".

IEB, arquivo Fernando de Azevedo, recorte do jornal A Ordem, 11/03/1930.

IEB, arquivo Fernando de Azevedo, recorte do jornal
Correio da Manhã. "O problema educacional e os cursos de férias nos Estados Unidos", Rio de Janeiro, $12 / 04 / 1930$.

IEB, arquivo Fernando de Azevedo, recorte do jornal Correio da Manhã. Rio de Janeiro, 12/04/1930.

IEB, arquivo Fernando de Azevedo, recorte do jornal A Ordem. "Como os Estados Unidos resolvem o problema do ensino", Rio de Janeiro, 11/03/1930.

IEB, arquivo Fernando de Azevedo, recorte do jornal O Globo. "O estudo directo dos mais modernos processos de ensino", Rio de Janeiro, 11/03/1930.

IEB, arquivo Fernando de Azevedo, recorte do jornal Diário Carioca. "Uma visão intelligente dos Estados Unidos", Rio de Janeiro, 07/03/1930.

IEB, arquivo Fernando de Azevedo, recorte do jornal O Globo. "O estudo directo dos mais modernos processos de ensino", Rio de Janeiro, 11/03/1930.

Recebido em: 08.04.2017 Aprovado em: 30.07.2017

Silmara Fátima Cardoso é Doutora em Educação pelo Programa de Pós-Graduação da Faculdade de Educação da Universidade de São Paulo (USP). Desenvolveu o projeto de pesquisa sob o título "Circulação de modelos pedagógicos e práticas educativas estrangeiras: experiências de educadores brasileiros no além-mar", financiado pela Fundação de Amparo à Pesquisa do Estado de São Paulo (FAPESP). Mestre em Educação pela Universidade de São Paulo (2011) e graduação em Pedagogia pela Universidade do Estado do Rio de Janeiro (2006). e-mail: sfcardoso2011@hotmail.com

Rua Tomaz Gonçalves, no 75, Bairro Vila Gomes, CEP: 05590-030, São Paulo/SP

Telefone: (11) 3721-7391 